\title{
HEAD TO HEAD
}

\section{Should Europe have a universal hepatitis B vaccination programme?}

WHO recommends that hepatitis B virus should be included in childhood vaccination programmes. Pierre Van Damme and colleagues argue that universal immunisation is essential to stop people becoming carriers but Tuija Leino and colleagues think that a targeted approach is a better use of resources in countries with low endemicity

\section{Pierre Van Damme professor ${ }^{1}$, Elke Leuridan postdoctoral researcher ${ }^{1}$, Greet Hendrickx project manager ${ }^{1}$, Alex Vorsters researcher ${ }^{1}$, Heidi Theeten assistant professor ${ }^{1}$, Tuija Leino senior medical officer $^{2}$, Mika Salminen research professorl ${ }^{3}$, Markku Kuusi senior medical officer ${ }^{3}$}

${ }^{1}$ Centre for the Evaluation of Vaccination, Vaccine and Infectious Disease Institute, University of Antwerp, Antwerp, Belgium; ${ }^{2}$ National Institute for Health and Welfare, Department of Vaccination and Immune Protection, Helsinki, Finland; ${ }^{3}$ National Institute for Health and Welfare, Department of Infectious Disease Surveillance and Control, Helsinki, Finland

\section{Yes-Pierre Van Damme, Elke Leuridan, Greet Hendrickx, Alex Vorsters, Heidi Theeten}

Hepatitis B occurs worldwide, with more than two billion people having been infected with the virus. ${ }^{1}$ Of these, about 240 million are living with chronic infection and at risk of cirrhosis and hepatocellular carcinoma, diseases that are estimated to cause 500 000-700 000 deaths a year. ${ }^{2}$ The risk of developing chronic infection decreases with age, occurring in up to $90 \%$ of infants infected during first year of life versus $5 \%$ of those infected as adults. ${ }^{1}$ Globally, newborns and infants are therefore the main target of hepatitis B immunisation programmes. In 1991 the World Health Organization set 1997 as the target for integrating hepatitis B vaccine into national immunisation programmes worldwide, ${ }^{3}$ and in 2010 the World Health Assembly adopted a resolution calling for a comprehensive prevention and control strategy, including universal hepatitis B vaccination and development of time specific immunisation goals. ${ }^{4}$ By the end of 2012, 179 countries-93\% of WHO member states-had added hepatitis B vaccine to their national newborn, infant, or adolescent immunisation programmes. ${ }^{2}$ It is time that all European countries followed suit.

\section{Infection in Europe}

About 14 million people are chronically infected with hepatitis $\mathrm{B}$ virus (HBV) in the WHO European region (53 countries), and 36000 die each year from HBV related causes. ${ }^{2}$ Forty seven European countries have a universal HBV immunisation programme as well as strategies for immunising high risk groups. Routine immunisation has created a generation of children and young adults with virtually no markers of HBV infection. Surveillance data from Italy, where universal infant as well as adolescent immunisation started in 1991, show a significant overall fall in the incidence of acute infection from $11 / 100000$ in 1987 to $0.9 / 100000$ in $2010 .{ }^{5}$ Furthermore, the prevalence of hepatitis B surface antigen ( $\mathrm{HBsAg}$ ) was $0 \%$ in 1-10 year olds, and $0.6 \%$ in 11-20 year olds in a seroepidemiological survey in Tuscany in 2011, significantly lower than the $5.1 \%$ in pre-vaccination cohorts (aged 41-50 years). ${ }^{6}$ Similarly, overall HBsAg prevalence decreased from $1.5 \%$ in 1989 to $0.7 \%$ in 2002 in Catalonia, Spain, where the universal adolescent programme started in $1990 .^{7}$

Six countries (Iceland, United Kingdom, Denmark, Norway, Sweden, and Finland), with acute hepatitis B incidences between 0.5/100 000 and 3.2/100 000, ${ }^{8}$ have not adopted universal immunisation, preferring to target only people at risk. However, the incidences in these countries are similar to those in Ireland and the Netherlands (1.7-1.8/100 000), ${ }^{8}$ where universal infant HBV immunisation has been recently introduced. Universal infant immunisation has been shown to be economically viable in low endemicity countries. In Ireland, at $€ 29$ ( $£ 25 ; \$ 38)$ per dose of the six component vaccine, universal infant immunisation costs $€ 37$ 018/life year gained, which compares favourably with other preventive programmes. ${ }^{9}$

\section{Problems of targeted vaccination}

Reliance on vaccination of groups at high risk of infection is seldom as effective as universal vaccination and is more difficult to implement. Considerable effort is needed to identify and reach people in the high risk groups - men who have sex with 
men, commercial sex workers, heterosexuals with multiple partners, and injecting drug users. ${ }^{10}$ Many are not identified until after they are infected, with median age at first vaccination around 30 years. ${ }^{10}$ Uptake is also a problem, with figures of less than $60 \%$ for the first dose in sex workers, ${ }^{11}{ }^{12}$ less than $50 \%$ in men who have sex with men, ${ }^{13}$ and less than $30 \%$ in injecting drug users. ${ }^{10}{ }^{14}$ In addition, over half of acute HBV infections in industrialised countries occur among people outside the risk groups, so targeted programmes will not prevent many infections. ${ }^{1}$ It is therefore not surprising that a focus on men who have sex with men and other risk groups has been shown not to control countries' transmission rates. ${ }^{10} 15$

A targeted approach also requires effective programmes to prevent perinatal HBV transmission, and these do not seem to be implemented effectively even in industrialised countries. ${ }^{16}$ Finally, the increasing number of immigrants from countries with higher endemicity moving to western Europe is leading to a substantial change in HBV epidemiology.$^{17}$ Transmission has been reported to spread horizontally or sexually beyond the immigrant communities; in the Netherlands, Germany, Finland, Denmark, Sweden, and UK, the cities with the highest proportion of foreign residents also have the highest hepatitis $\mathrm{B}$ incidence (in migrants and non-migrants). ${ }^{18}$

The low vaccination rate in the so called risk groups, where exposure is substantial, and the fact that many become infected before immunisation is offered remain of particular concern. The six western European countries without universal immunisation should reconsider following WHO recommendations. Universal programmes are the optimal way to ensure timely high coverage of the risk groups of tomorrow.

\section{No-Tuija Leino, Mika Salminen, Markku Kuusi}

Carriers of hepatitis B virus (HBV) are a source of infection and likely to experience problems such as cirrhosis and cancer. As acute HBV infection is often mild and rarely life threatening, the main target of any preventive intervention programmes, including immunisation, should be to prevent people becoming carriers. In high prevalence countries HBV infection is obtained mostly during childhood, when the risk of lifelong carriage is up to $90 \% .{ }^{1}$ But in countries with low or very low prevalence, infection is normally acquired through risk behaviour by young adults. Such infections result in lifelong virus carriage in only $1-5 \%$ of cases. ${ }^{19}$ In fact, among adolescents and adults, each carrier would have to transmit the virus to at least 20 people to produce a further carrier. Thus, immigration is by far the main source of new carriers in low endemicity countries, ${ }^{20-24}$ and universal childhood vaccination would have a minimal effect on the prevalence of carriers. ${ }^{25}$ Preventive efforts are therefore better directed elsewhere.

\section{Antenatal screening is the key}

The priority in Europe should be a universal and effective antenatal HBV screening programme. Antenatal screening and high compliance with immunisation when indicated are vital for preventing chronic carriage in all countries, even those with universal infant vaccination programmes. Targeted neonatal of administration of immunoglobulin is essential to prevent maternal transmission, which is the most likely route of infant infection in countries with low prevalence. Antenatal screening also allows for detection and prevention of other diseases, such as HIV.

\section{In the best interest of immigrants}

In Finland, more than a third of acute cases of HBV infection were detected among immigrants during 2008-12. Transmission has also been shown to continue among immigrant communities in other low endemicity countries. ${ }^{26}{ }^{27}$ Therefore, family members, especially newborns of mothers from middle or high endemic countries, should be vaccinated, ${ }^{24}$ as is done, for example, in Norway. ${ }^{28}$ Screening of immigrants is not essential in preventing $\mathrm{HBV}$ transmission from immigrant children to other children, ${ }^{22}{ }^{29}$ but it does allow treatment of possible chronic infections. New antiviral drugs are effective and result in a sustained response in most patients, reducing the disease burden and also the risk of further transmission. ${ }^{30}$

\section{Targeted programmes do work}

When a very low incidence infection is unevenly distributed and the risk groups of the disease are well known, selective vaccination is an intuitive option. In a theoretical case, a targeted programme would clearly be more cost effective than universal vaccination since only those who will eventually be exposed to HBV are vaccinated, producing a number needed to treat of not much higher than 1 . Indirect effects, such as the decreased risk of infection in close contacts who are likely to share the same risk behaviour, are also stronger in targeted vaccinations as disease risk is not universally distributed. ${ }^{31}$

Selective strategies are, however, highly dependent on their ability to sufficiently identify, reach, and fully immunise people in the risk groups. It is essential to offer the vaccine in low threshold settings, such as needle exchange locations, which are also central for harm reduction of other drug related problems. Mathematical modelling suggests that liberal and extended targeted programmes are effective, ${ }^{25}$ and this is supported by the falling incidence of acute hepatitis B in various northern European countries (http://data.euro.who.int/cisid, www.epinorth.org).

Medical and dental care or blood products, which have in the past led to iatrogenic infections, are increasingly safe in low endemicity countries. Hepatitis A and B combination vaccine is widely used in northern Europe, preventing transmission linked to travelling in endemic countries. Furthermore, with universal infant immunisation programmes operating in former high incidence countries since early 2000, infection pressure from these countries should diminish, not increase. As Hahne and colleagues stated, the prevalence of HBV infection in low endemicity countries depends on global rather than national immunisation policies. ${ }^{21}$

Moreover, universal vaccination programmes never reach everyone, even in northern Europe. In fact, immigrants, ethnic minorities, and children of families with social problems or heavy drug and alcohol use are the most difficult groups to reach. Hepatitis B, unlike other diseases presently protected by childhood vaccinations, is associated with social determinants of increased risk behaviour. It is therefore not clear that universal vaccination would result in a substantial decrease of acute cases in the coming decades in low endemicity countries.

\section{Ethical use of resources}

Cost effectiveness is not the main argument for public health interventions but has to be considered. In countries with very low incidence of hepatitis B the cost effectiveness of universal immunisation has not been shown. ${ }^{31} 32$ Establishing a universal immunisation programme to prevent rare iatrogenic cases is hardly a justified use of limited resources. Solid cost effectiveness analysis is challenging, time consuming, and 
requires dynamic transmission modelling with all its critical assumptions. These analyses, as well as decisions on universal programmes have to be based on local data on transmission, treatment, and vaccination costs. Costs and effects also need to be discounted, as they are for other healthcare interventions. Without good evidence neither parents nor decision makers will accept an infant immunisation programme. Harmonisation of European vaccination programmes is not a goal in itself, since infrastructure as well as epidemiology clearly differ. ${ }^{33}$

Competing interests: The authors have read and understood the BMJ Group policy on declaration of interests and declare the following interests: PvD is head of the Vaccine and Infectious Disease Institute at the University of Antwerp, which is a WHO collaborating centre for the prevention and control of infectious diseases; chair of the European Technical Advisory Group of Experts on immunisation at WHO EURO; and executive secretary of the Viral Hepatitis Prevention Board, which is supported by unrestricted grants from the vaccine industry (GlaxoSmithKline Biologicals, Sanofi Pasteur, and Merck). PvD acts as chief and principal investigator for vaccine trials, for which the university obtains research grants from vaccine manufacturers.

Provenance and peer review: Commissioned; not externally peer reviewed.

1 Van Damme P, Ward J, Shouval D, Wiersma S, Zanetti A. Hepatitis B vaccines. In: Plotkin S, Orenstein W, Offit P. Vaccines. 6th ed. Elsevier Saunders, 2013:205-34.

2 WHO. Prevention and control of viral hepatitis infection: framework for global action, 2012. www.who.int/csr/disease/hepatitis/en/index.html.

3 WHO. Hepatitis B vaccines. WHO position paper. Weekly Epidemiol Rec 2009;40:405-20

4 WHO. Sixty third World Health Assembly: viral hepatitis, WHA 63.18. 2010. http://apps. who.int/gb/ebwha/pdf_files/WHA63/A63_R18-en.pdf.

5 Romano L, Paladini S, Van Damme P, Zanetti AR. The worldwide impact of vaccination on the control and protection of viral hepatitis B. Dig Liver Dis 2011:43(suppl 1):S2-7.

6 Boccalini S, Pellegrino E, Tiscione E, Pesavento G, Bechini A, Levi M, et al. Sero-epidemiology of hepatitis B markers in the population of Tuscany, central Italy, 20 years after the implementation of universal vaccination. Hum Vaccines Immunotherapeutics 2013;9:1-6.

7 Salleras L, Dominguez A, Bruguera M, Plans P, Costa J, Cardenosa N, et al. Declining prevalence of hepatitis B virus infection in Catalonia (Spain) 12 years after the introduction of universal vaccination. Vaccine 2007:25:8726-31.

8 Rantala M, van de Laar M. Surveillance and epidemiology of hepatitis B and C in Europe-a review. Eurosurveillance 2008;13:1-7.

9 Tilson L, Thornton L, O'Flanagan D, Johnson H, Barry M. Cost effectiveness of hepatitis $B$ vaccination strategies in Ireland: an economic evaluation. Eur $J$ Public Health 2008;18:275-8.

10 Van Houdt R, Koedijk FD, Bruisten SM, Coul EL, Heijnen ML, Waldhober Q, et al. Hepatitis $B$ vaccination targeted at behavioural risk groups in the Netherlands: does it work? Vaccine 2009;27:3530-5

11 Baars JE, Boon BJ, Garretsen HF, van de Mheen D. Vaccination uptake and awareness of a free hepatitis $B$ vaccination program among female commercial sex workers. Womens Health Issues 2009;19:61-9.
12 Wouters K, Leuridan E, Van Herck K, Van Ardenne N, Roelofs I, Mak R, et al. Compliance and immunogenicity of two hepatitis $\mathrm{B}$ vaccination schedules in sex workers in Belgium. Vaccine 2007;25:1893-900

13 Baars JE, Boon BJ, Garretsen HF, van de Mheen D. The reach of a hepatitis B vaccination programme among men who have sex with men. Eur J Public Health 2011;21:333-7.

14 Day CA, White B, Dore GJ, van Beek I, Rodgers C, Cunningham P, et al. Hepatitis B virus among injecting drug users in Sydney, Australia: prevalence, vaccination and knowledge of status. Drug Alcohol Depend 2010;108:134-7.

15 Beeching NJ. Hepatitis B infections. BMJ 2004;329:1059-60.

16 Heininger U, Vaudaux B, Nidecker M, Pfister RE, Posfay-Barbe KM, Bachofner M, et al. Evaluation of the compliance with recommended procedures in newborns exposed to HBsAg-positive mothers: a multicenter collaborative study. Pediatr Infect Dis $J$ 2010;29:248-50.

17 Chu JJ, Wörmann T, Popp J, Pätzelt G, Akmatov MK, Krämer A, et al. Changing epidemiology of hepatitis $B$ and migration-a comparison of six northern and north-western European countries. Eur J Public Health 2012 Jun 8 [Epub ahead of print].

18 Cai W, Poethko-Muller C, Hamouda O, Radun D. Hepatitis B virus infections among children and adolescents in Germany: migration background as a risk factor in a low seroprevalence population. Pediatr Infect Dis J 2011;30:19-24.

19 Liaw YF, Chu CM. Hepatitis B virus infection. Lancet 2009:373:582-92.

20 Marschall T, Kretzschmar M, Mangen MJJ, Schalm S. High impact of migration on the prevalence of chronic hepatitis B in the Netherlands. Eur J Gastroenterol Hepatol 2008;20:1214-25.

21 Hahne S, Ramsay M, Balogun K, Edmunds WJ, Mortimer P. Incidence and routes of transmission of hepatitis B virus in England and Wales 1995-2000: implications for immunisation policy. J Clin Virol 2004:29:211-20.

22 Lindh M, Horal P, Norkrans G. Acute hepatitis B in western Sweden-genotypes and transmission routes. Infection 2000;28:161-3.

23 Fisker N, Pedersen C, Lange M, Nguyen NT, Nguyen KT, Georgsen J, et al. Molecular epidemiology of hepatitis B virus infections in Denmark. J Clin Virol 2004;31:46-52.

24 Kretzschmar M, Mangen MJ, Van de Laar M, De Wit A. Model based analysis of hepatitis $B$ vaccination strategies in the Netherlands. Vaccine 2009;27:1254-60.

25 Kretzschmar M, De Wit A, Smits L, Van de Laar M. Vaccination against hepatitis B in low endemic countries. Epidemiol Infect 2002;128:229-44.

26 Aweis D, Brabin BJ, Beeching NJ, Bunn JE, Cooper C, Gardner K, et al. Hepatitis B prevalence and risk factors for HBsAg carriage amongst Somali households in Liverpool. Commun Dis Public Health 2001;4:247-52.

27 Mahoney FJ, Lawrence M, Scott C, Le Q, Lambert S, Farley TA. Continuing risk for hepatitis B virus transmission among Southeast Asian infants in Louisiana. Pediatrics 1995;96:1113-6.

28 Rimseliene G. Epidemiology of acute and chronic hepatitis virus infections in Norway 1992-2007. European Scientific Conference on Applied Infectious Disease Epidemiology, Stockholm, 27 October 2009

29 Gjørupa IE, Skinhøja P, Böttiger B, Plesnerb AM. Changing epidemiology of HBV infection in Danish children. J Infect 2003:47:231-5.

30 European Association for the Study of Liver. EASL clinical practice guidelines: management of chronic hepatitis B infection. J Hepatology 2012;57:167-95.

31 Beutels $\mathrm{P}$. Economic evaluation of hepatitis $\mathrm{B}$ immunization: a global review of recen studies (1994-2000). Health Econ 2001;10:751-74.

32 Edmunds WJ. Universal or selective immunisation against hepatitis B virus in the United Kingdom? A review of resent cost-effectiveness studies. Common Sis Public Health 1998;1:221-8.

33 Nardone A, Anastassopoulou CG, Theeten H, Kriz B, Davidkin I, Thierfelder W, et al. A comparison of hepatitis B seroepidemiology in ten European countries. Epidemiol Infect 2009;137:961-9.

Cite this as: BMJ 2013;346:f4057

(c) BMJ Publishing Group Ltd 2013 